\title{
Prevalence of Obesity and Knowledge of Health Risk Associated with Obesity among Female Adolescents in Jordan
}

\author{
Lubna Mohammed Thaher ${ }^{1}$, Jafar Alasad ${ }^{2}$, Mahmoud Maharmeh ${ }^{2}$, Ibrahim Salami2 \\ ${ }^{1}$ Ministry of Health, Amman, Jordan \\ ${ }^{2}$ School of Nursing, University of Jordan, Amman, Jordan \\ Email: Lubnathaher@yahoo.com, *jalasad@ju.edu.jo,m.maharmeh@ju.edu.jo, i.salami@ju.edu.jo
}

How to cite this paper: Thaher, L.M., Alasad, J., Maharmeh, M. and Salami, I. (2018) Prevalence of Obesity and Knowledge of Health Risk Associated with Obesity among Female Adolescents in Jordan. Open Journal of Nursing, 8, 60-68. https://doi.org/10.4236/ojn.2018.81005

Received: December 20, 2017

Accepted: January 23, 2018

Published: January 26, 2018

Copyright $\odot 2018$ by authors and Scientific Research Publishing Inc. This work is licensed under the Creative Commons Attribution International License (CC BY 4.0).

http://creativecommons.org/licenses/by/4.0/

\begin{abstract}
Introduction: Overweight and obesity is major health challenge worldwide. Purpose: The purpose of the study was to estimate the prevalence of overweight and obesity and assess knowledge on the health risks associated with obesity among female adolescents in the Jordanian capital Amman. Method: A cross-sectional survey of 782 female adolescents was conducted using random sampling technique. Height and weight were measured and body mass index for age was used to determine overweight and obesity depending on International Obesity Task Force standers. Obesity risk knowledge-10 scale was used to assess knowledge level among female adolescents. Results: The prevalence of overweight and obesity among female adolescents were $34.9 \%$ and $12.5 \%$ respectively. Knowledge about health risk associated with obesity among female adolescents was low. Ninety five percent of participant had low to moderate knowledge about health risk associated with obesity. Conclusions: Prevalence of overweight and obesity among Jordanian female adolescents was high. Overweight and obesity is a serious public health problem among female adolescents in Jordan.
\end{abstract}

\section{Keywords}

Obesity, Overweight, Female Adolescents, Jordan

\section{Introduction}

Overweight and obesity is major health challenge in both developed and developing countries. Forty four percent of diabetes, $23 \%$ of ischemic heart disease and up to $41 \%$ of cancer cases are attributed to overweight and obesity [1]. In 
2008 it was estimated that more than 1.4 billion people worldwide were overweight and at least 500 million of them were clinically obese [1]. Obese children tend to become obese adults [2]. In addition, obesity associated with varied health consequence such as decreased life expectancy and bad quality of life [1].

In recent decades, the prevalence of obesity among adolescents has increased worldwide. Between 1980 and 2013 obesity increased by nearly $50 \%$ worldwide [3]. In 2013, overweight or obesity among girls and boys were (22\% and $24 \%$ ) respectively in developed countries and nearly $13 \%$ were found to be obese or overweight [3]. The prevalence of obesity among adults in the United State of America is $35.7 \%$, and approximately $17 \%$ among adolescent. The estimated medical costs associated with obesity was approximately $\$ 147$ billion for year 2008 , and the total spending of the US economy on obesity and overweight was $\$ 270$ billion including medical care and loss of production due to illnesses and deaths caused by obesity [4]. In China, over $20 \%$ of children and adolescents are overweight or obese [5]. In a study conducted among adolescents aged from 10 to 16 years in 34 countries (primarily European) revealed that Malta and the United States were the highest prevalence of overweight and obesity [6].

Studies conducted in Arab countries indicated that obesity remains a significant problem in most countries despite economic and cultural disparities among them. Musaiger [7] sated that obesity in preschool children range from 3\% - 9\%, and $12 \%$ - 25\% among primary school children, while adolescents' obesity ranged from $15 \%$ - $45 \%$. In a study conducted in seven Arab countries, the overall prevalence of overweight and obesity range from $18 \%$ to $44 \%$ and the prevalence among male adolescents were as the following: Kuwait (25.6\% and 34.8\%), Jordan (21.6\% - 10.6\%), Syria (20.3\% and 6.7\%), United Arab Emirates (16.8\% and $19.1 \%$ ), Libya (16.4\% and 19.6\%), Palestine (12.7\% and 5\%), Algeria (9.4\% and $4.1 \%$ ) respectively [8].

Adolescence is the period in human growth that associated with many physical and biological changes. These changes include increase in fat, greatest amount of growth in height and weight, increase muscle mass and onset of menarche for girls [9]. Obese children usually experience psychosocial problems include social stigmatization and discrimination (marginalization, isolation) which has adverse effect on their health [10]. Adolescents and children who are obese and overweight may grow up with a lower self-esteem and lack of confidence [11]. Factors contributing to obesity among adolescent include lack of community places to get adequate physical activities, lack of healthy food and insufficient consumption of vegetables and fruits, too long time spent in sedentary activities such as video games and television viewing [12] [13].

In the last decade the prevalence of overweight and obesity among Jordanian adolescents has increased [14]. Obese adolescents face a great risk of health problems including hypertension, sleep apnea, diabetes mellitus, high blood lipids, asthma, and psychosocial problems including isolation and low self-esteem [15]. Accurate estimates of the prevalence of obesity among adolescence in Jordan would lead to establishing an effective sustainable obesity prevention strate- 
gy. The purpose of the study was to estimate the prevalence of overweight and obesity; and assess knowledge on the health risks associated with obesity among female adolescents in the capital of Jordan.

\section{Method}

A descriptive, cross-sectional design was used to assess prevalence of obesity and knowledge of health risk associated with obesity among adolescents in the Jordanian capital Amman. The target population present all female adolescents studding at schools in the capital Amman aged $13-18$ years old $\left(7^{\text {th }}, 8^{\text {th }}, 9^{\text {th }}, 10^{\text {th }}\right.$, $11^{\text {th }}, 12^{\text {th }}$ grades). The estimated number of private and public schools that have the target population in Amman is (5004). These schools have 300,000 female students (Ministry of education) [16]. The study sample was female students selected from primary and secondary, private and public schools. Twenty five schools were selected using random sampling technique (computer generated random numbers) from the total number of schools that have the target population. Then in each school, 1 section from each grade was randomly selected.

The total sample size required for the study was calculated based on confidence level (CL) of $95 \%$, margin of error $5 \%$, population size of 300,000 . The sample size required to represent the population was found to be 384 female students. However, 782 students were surveyed to improve representative and decrease margin error. With this sample (782) the confidence level improved to reach $99 \%$ and margin error was $4.6 \%$.

Data was collected using structured interview to fill in the study questionnaire and take height and weight measurement by one data collector to maintain consistency. The study questionnaire consists of three parts. Part one was demographic data, part two height, weight and BMI measurement, part three was the obesity risk knowledge scale (ORK-10). The ORK-10 was developed by Swift, Glazerbrook and Macdonald [17] to assess knowledge about risks associated with obesity. It consist of 10 of items with a three options $(1=$ True, $2=$ don't know, 3 = False. If students get the question correct they would get one point, if they were wrong or they select "don't know" the question was scored zero points. The maximum total score of the ORK-10 is 10 and the minimum is zero. Higher scores represent better knowledge and awareness about health risks associated with obesity. The ORK-10 scale has internal consistency (Cronbach's alpha) of $>0.7$, and was found to meet standard psychometric criteria for reliability and validity [17].

Anthropometric measurements which include weight and height were taken for all participants in light clothing and no shoes. Weight was measured using one digital scale (Digital Glass Personal Scale - QF-2003B) to the nearest $0.1 \mathrm{~kg}$. Height was measured using measuring tape on the wall with participant standing without shoes, looking straight with heels together and recorded to the nearest $0.5 \mathrm{~cm}$. The reliability of the anthropometric measures was maintained through the use of the same protocol by the same person using the same equipment. The digital weight scale was used according to manufacturer instructions and cali- 
brated before data collection and each time it is moved from place. BMI was calculated as the ratio of weight (kilograms) to the square of height (meters). Obesity is categorized according to age-sex specific percentiles of BMI using the International obesity task force (IOTF) for age growth charts [18].

The study was ethically approved by Institutional review board (IRB) at the University of Jordan and Ministry of Education. Participation in the study was voluntary and based on inform consent from students and their parents.

\section{Results}

The study included 782 female adolescents, aged between 13 - 18 years with a mean age of 15.1 (SD, 1.34) years. Fifty five percent (434) were in the age group 13 - 15 years. Forty three percent (338) of participants were in $7-9$ grade and $56.8 \%$ were in $10-12$ grades. In addition, $63.3 \%$ (495) were from public schools. Fifty one percent (404) of participant didn't participate in daily exercise, 59\% (461) don't eaten vegetables or fruits every day, and 59.6\% (460) eat once monthly outside home. Fifty percent (392) usually walk to school and 79.2\% (619) have regular menstrual cycle (Table 1).

Table 1. Characteristics of participants $(\mathrm{N}=782)$.

\begin{tabular}{|c|c|c|c|}
\hline \multicolumn{2}{|l|}{ Variable } & \multirow{2}{*}{$\frac{\text { Number of students }}{434}$} & \multirow{2}{*}{$\frac{\text { Percentage (\%) }}{55.5}$} \\
\hline A ge & 13 - 15 years & & \\
\hline Age & 15.5 - 18 years & 348 & 44.5 \\
\hline \multirow{2}{*}{ Grade } & $7-9$ grade & 338 & 43.2 \\
\hline & $10-12$ grades & 444 & 56.8 \\
\hline \multirow{2}{*}{ School type } & Private & 287 & 36.7 \\
\hline & Public & 495 & 63.3 \\
\hline \multirow{3}{*}{ Fathers education level } & Primary & 81 & 10.4 \\
\hline & Secondary & 390 & 49.9 \\
\hline & University & 311 & 39.8 \\
\hline \multirow{3}{*}{ Mothers education level } & Primary & 61 & 7.8 \\
\hline & Secondary & 433 & 55.4 \\
\hline & University & 288 & 36.8 \\
\hline \multirow{2}{*}{ Father an employee } & Yes & 709 & 90.7 \\
\hline & No & 73 & 9.3 \\
\hline \multirow{2}{*}{ Mother an employee } & Yes & 135 & 17.3 \\
\hline & No & 647 & 82.7 \\
\hline \multirow{2}{*}{ Daily exercise (at least $30 \mathrm{mint}$ ) } & Yes & 378 & 48.3 \\
\hline & No & 404 & 51.7 \\
\hline \multirow{2}{*}{ Eat vegetables or fruits } & Every day & 321 & 41 \\
\hline & Not every day & 461 & 59 \\
\hline \multirow{3}{*}{ Eat outside home } & Daily & 35 & 4.5 \\
\hline & Weekly & 281 & 35.9 \\
\hline & Monthly & 466 & 59.6 \\
\hline \multirow{2}{*}{ Usually walk to school } & Yes & 392 & 50.1 \\
\hline & No & 390 & 49.9 \\
\hline \multirow{2}{*}{ Menstrual period } & Regular & 619 & 79.2 \\
\hline & Irregular & 163 & 20.8 \\
\hline
\end{tabular}


Overweight and obesity were categorized according to age-sex specific percentiles of body mass index (BMI) using the International Obesity Task Force (IOTF) recommendations (Cole et al.) [18]. Participants' Mean BMI was 23 (SD \pm 3.95 ) with a ranged from $14-38 \mathrm{~kg} / \mathrm{m}^{2}$. The prevalence of underweight was $2.7 \%$ (21), adolescents with normal weight were $49.9 \%$ (390), with overweight $34.9 \%$ (273) and with obesity $12.5 \%$ (98). The overall prevalence of adolescent who are overweight and obese were $47.4 \%$ (Table 2).

Mean level for knowledge was $4.57(\mathrm{SD} \pm 1.86)$ with a ranged from $0-10$. Forty eight percent (377) of participants had poor knowledge (score 0 - 4); 46.8\% (366) had moderate knowledge (score 5 - 7), and 5\% (39) had good knowledge (score 5 - 7) (Table 3). Adolescents whose mothers have higher education level (University degree) have mean BMI lower than those whose mothers have lower education levels $(\mathrm{P}<0.05)$. The findings also revealed that participants aged 15 years and more, studding in public schools, and eat vegetables or fruits in daily basis have better knowledge about health risk associated with obesity $(\mathrm{P}<0.05)$.

\section{Discussion}

The present study was conducted with an attempt to identify the obesity and overweight in adolescent age group as a public health problem. The findings indicated that the prevalence of overweight and obesity in the study population were extremely high compared to the findings of other studies. Abu-Baker and Daradkeh [14] found that prevalence of overweight and obesity in the city of Irbid among school students was $15.7 \%$ and $8.7 \%$ respectively. A study conducted in India by Mandal [19] show that $28.5 \%$ were overweight and $4.2 \%$ were obese among 571 girl students aged 12 - 18 years, which is extremely low compared to the present study. In Amman, Jordan [20] studies reported that overweight and obesity among females aged $15-18$ years were $24.4 \%$ and $8.9 \%$ respectively. Also the prevalence was nearly the same among Egyptians adolescent [21]. In addition, the findings of present study indicated that obesity was lower than the $20.6 \%$

Table 2. Prevalence of overweight and obesity $(\mathrm{N}=782)$.

\begin{tabular}{ccc}
\hline BMI (mean = 23, SD 3.95) & Number of students & Percentage (\%) \\
\hline Under weight $(\mathrm{BMI}=13-17)$ & 21 & 2.7 \\
Normal weight $(\mathrm{BMI}=17.1-22.5)$ & 390 & 49.9 \\
Overweight $(\mathrm{BMI}=22.6-27.6)$ & 273 & 34.9 \\
Obese (BMI = 27.7 and more) & 98 & 12.5 \\
Overweight and obese & 371 & 47.4 \\
\hline
\end{tabular}

Table 3. Level of knowledge about health risk associated with obesity.

\begin{tabular}{ccc}
\hline Knowledge level $($ mean $=4.57$, SD 1.86) & Number of students & Percentage (\%) \\
\hline Poor knowledge $($ score $=0-4)$ & 377 & 48.2 \\
Moderate knowledge $($ score $=5-7)$ & 366 & 46.8 \\
Good knowledge $($ score $=8-10)$ & 39 & 5 \\
\hline
\end{tabular}


obese among Kuwaiti adolescents reported by [8]. The higher prevalence of overweight and obesity in this age group may be due to fact that students live in sedentary life style while decreasing physical activity and the school, homes environment tend to discourage a healthy lifestyle. This also may be due to their eating habits.

The findings of this study supported previous study by [22] who found that the ORK-10 was low amongst all participants but in their parent slightly higher which may have been due to their life experience. Similar findings were apparent in UK prospective study that measured ORK-10 amongst 66 patients attending weight management clinic [23]. Overall, the mean ORK-10 score was relatively low among all patients; however this result may be related to the fact that the study had small sample size. Findings from two previous studies were also different to finding from [24], who administered the ORK-10 scale to 138 students at Chester University. The study found that ORK-10 scores amongst the nutrition and dietetic students were relatively high mean (9.06).

An interesting finding of present study was a significant relationship between mother education level and obesity. This finding was consistent with that of [25] who found that a significant relationship between occurrence of overweight and obesity and maternal education level. Similar findings were apparent in a study conducted by [26] that revealed an association between maternal education level and adolescence overweight or obesity. In Indian, [27] reported that lower educational level of mothers was considered as a risk factor for obesity and overweight among children. However, Bhuiyan [28] study of seven urban school children and adolescents in Bangladesh reported that adolescents' obesity was not significantly associated with mothers' educational level.

The study also found that students who were more than 15 years of age had significantly higher ORK-10 scores than students who were 15 or below. This finding was consistent with a study conducted at Coventry University among 40 adolescents which revealed that older adolescents scored significantly higher on ORK-10 scale than younger adolescents [29]. Across sectional study used the ORK-10 scale to measure knowledge about obesity risk amongst 94 adolescent and their parent [22]. The findings revealed that ORK-10 score was higher among older participants. This may be related to the fact that the parent have more life experience. Findings from the two previous studies are also similar to the finding from [30] at the University of Nottingham. The researchers reported a higher score in students who were final year of study.

Another finding of this study was that school type and eating vegetables or fruits were significantly associated with higher students' knowledge about obesity risk. Students who were studying in public school had significantly higher ORK-10 scores than students who were studying in private school. Students who eat vegetables or fruits every day had higher ORK-10 scores than students who were not. Studies supporting or refuting relationship between school type and eating vegetables or fruits with knowledge is lacking. 


\section{Conclusion}

Overweight and obesity is a serious public health problem among female adolescents in Jordan. The prevalence of overweight and obesity among female adolescents were $34.9 \%$ and $12.5 \%$ respectively. Knowledge about health risk associated with obesity among female adolescents was low.

\section{References}

[1] World Health Organization. Obesity and Overweight Fact Sheet 311. WHO, Geneva, 2012.

[2] Guo, S., Chumlea, W. and Roche, A. (2002) Predicting Overweight and Obesity in Adulthood from Body Mass Index Values in Childhood and Adolescence. The American Journal of Clinical Nutrition, 76, 653-658.

[3] Institute for Health Metrics and Evaluation. Nearly One-Third of the World's Population is Obese or Overweight, New Data Show (2013).

http://www.healthdata.org/news-release/nearly-one-third-world\%E2\%80\%99s-pop ulation-obese-or-overweight-new-data-show

[4] World Health Organization. World Health Statistics 2014. http://apps.who.int/iris/bitstream/10665/112738/1/9789240692671_eng.pdf

[5] Shan, X.Y., Xi, B., Cheng, H., et al. (2010) Prevalence and Behavioral Risk Factors of Overweight and Obesity among Children aged 2-8 in Beijing, China. International Journal of Pediatric Obesity, 5, 383-389. https://doi.org/10.3109/17477160903572001

[6] Janssen, L., Katzmarzyk, P.T., Boyce, W.F., et al. (2005) Health Behavior in School-Aged Children Obesity Working Group: Comparison of Overweight and Obesity Prevalence in School-Aged Youth from 34 Countries and Their Relationship with Physical Activity and Dietary Patterns. Obesity Reviews, 6, 123-132. https://doi.org/10.1111/j.1467-789X.2005.00176.x

[7] Musaiger, A. (2004) Overweight and Obesity in the Eastern Mediterranean Region: Can We Control it? East Mediterr Health, 10.

[8] Musaiger, A., AL-Mannai, M., Tayyem, R., et al. (2012) Prevalence of Overweight and Obesity among Adolescents in Seven Arab Countries: A Cross-Cultural Study. Journal of Obesity, 2012, Article ID: 981390.

[9] Stang, J. and Stary, M. (2005) Guidelines for Adolescent Nutrition Services. http://www.epi.umn.edu/let/pubs/img/adol-chl.pdf_book.shtm

[10] Dietz, W.H. (1998) Health Consequences of Obesity in Youth: Childhood Predictors of Adult Disease. Pediatrics, 101, 518-525.

[11] Strauss, R.S. (2000) Childhood Obesity and Self-Esteem. Pediatrics, 105, e15. https://doi.org/10.1542/peds.105.1.e15

[12] Lowry, R., Wechsler, H., Galuska, D.A., et al. (2002) Television Viewing and It Associations with Overweight, Sedentary Lifestyle and Insufficient Consumption of Fruits and Vegetables among US High School Students: Differences by Race, Ethnicity and Gender. Journal of School Health, 72, 413-421. https://doi.org/10.1111/j.1746-1561.2002.tb03551.x

[13] Eisemann, J.C., Barrtee, R.T. and Wang, M. (2002) Physical Activity, TV, Viewing and Weight in US Youth: 1999 Youth Risk Behavior Survey. Obesity Research, 10, 379-385. https://doi.org/10.1038/oby.2002.52

[14] Abu Baker, N.N. and Daradkeh, S.M. (2010) Prevalence of Overweight and Obesity 
among Adolescents in Irbid Governorate, Jordan. Eastern Mediterranean Health Journal, 16, 657-662.

[15] Gossans, L., Braet, C. and Decaluwe, V. (2007) Loss of Control over Eating in Obese Youngsters. Behavior Research and Therapy, 45, 1-9. https://doi.org/10.1016/j.brat.2006.01.006

[16] Ministry of Education (2014) Statistical Report for the Year School. 17, 73. http://www.moe.gov.jo

[17] Swift, J.A., Glazebrook, C. and Macdonald, I. (2006) Validation of a Brief, Reliable Scale to Measure Knowledge about the Health Risks Associated with Obesity. International Journal of Obesity, 30, 661-668. https://doi.org/10.1038/sj.ijo.0803165

[18] Cole, T.J., Bellizzi, M.C., Flegal, K.M., et al. (2000) Establishing a Standard Definition for Child Overweight and Obesity Worldwide: International Survey. BMJ, 320, 1240-1243. https://doi.org/10.1136/bmj.320.7244.1240

[19] Mandal, A. and Mandal, G. (2012) Prevalence of Overweight and Obesity among the Urban Adolescent English Medium School Girls of Kolkata, India. Italian Journal of Public Health, 9, 3.

[20] Musaiger, A., AL-Manni, M. and Tayyem, R. (2013) Prevalence of Overweight and Obesity among Female Adolescents in Jordan: A Comparison between Two International Reference Standards. Pakistan Journal of Medical Sciences, 29, 676-678. https://doi.org/10.12669/pjms.292.3222

[21] Talat, M. and Shahat, E. (2016) Prevalence of Overweight and Obesity among Preparatory School Adolescents in Urban Sharika Governorate Egypt. Egyptian Pediatric Association Gazette, 64, 20-25. https://doi.org/10.1016/j.epag.2015.11.004

[22] Rutkowesk, E.M. and Connelly, C.D. (2011) Obesity Risk Knowledge and Physical Activity in Families of Adolescents. Journal of Pediatric Nursing, 26, 51-57. https://doi.org/10.1016/j.pedn.2009.12.069

[23] Swift, J.A., Glazebrook, C., Anness, A., et al. (2009) Obesity-Related Knowledge and Beliefs in Obese Adults Attending a Specialist Weight Management Service: Implications for Weight Loss over 1 Year. Patient Education and Counseling, 74, 70-76. https://doi.org/10.1016/j.pec.2008.07.045

[24] Giglia, M. (2012) Knowledge and Attitudes of Obesity in University Students. Unpublished Master's Thesis, University of Chester, Chester. http://chesterrep.openrepository.com/cdr/handle/10034/298988

[25] Giugliano, R. and Carneiro, E.C. (2004) Factors Associated with Obesity in School Children. Journal of Pediatrics, 80, 17-22. https://doi.org/10.2223/1128

[26] Patsopoulou, A., Tsimtsiou, Z. and Katsioulis, A. (2015) Prevalence and Risk Factors of Overweight and Obesity among Adolescents and Their Parents in Central Greece (FETA Project). International Journal of Environmental Research and Public Health, 13, 83. https://doi.org/10.3390/ijerph13010083

[27] Mozaffari, H. and Nabaei, B. (2007) Obesity and Related Risk Factors. The Indian Journal of Pediatrics, 74, 265-267. https://doi.org/10.1007/s12098-007-0041-y

[28] Bhuiyan, M., Zaman, S.H. and Ahamed, T. (2013) Risk Factors Associated with Overweight and Obesity among Urban School Children and Adolescents in Bangladesh: A Case-Control Study. BMC Pediatrics, 13, 72. https://doi.org/10.1186/1471-2431-13-72

[29] Ward, G. and Amirabdollahian, F. (2011) A Study to Investigate the Knowledge of Coventry University Students Regarding the Health Risks Associated with Obesity. Journal of Human Nutrition and Dietetics, 24, 307-308. 
https://doi.org/10.1111/j.1365-277X.2011.01175_40.x

[30] Swift, J.A., Sheard, C. and Rutherford, M. (2007) Trainee Health Care Professional's Knowledge of the Health Risks Associated with Obesity. Journal of Human Nutrition and Dietetics, 20, 599-604. https://doi.org/10.1111/j.1365-277X.2007.00826.x 